\title{
Imagery ability in Boccia: Comparison among federate athletes from different medical sport groups
}

\author{
André Pinto Amorim¹, Bruno Travassos ${ }^{1,2^{*}}$, Pedro Duarte-Mendes 3,4
}

ARTIGO ORIGINAL | ORIGINAL ARTICLE

\begin{abstract}
The aim of this study was to analyse and compare movement visualization ability in federate and nonfederate Boccia athletes, and among federate Boccia medical sport groups. Forty-two Boccia athletes (Federate $\mathrm{N}=24$; Non-federate $\mathrm{N}=18$ ) at an average age of $35.8(\mathrm{SD}=11.19)$ participated in this study. The Portuguese version of Movement Imagery Questionnaire - 3 (MIQ-3), was used for this study. The participants were evaluated on the internal and external visual imagery. Statistics was carried out following the method of interference based on the magnitude of the effects. Results showed a great effect of expertise in imagery ability. The comparison between federate and non-federate Boccia athletes showed a great effect in the Internal Visual subscale and a moderate effect in the External Visual subscale. It was also observed differences between athletes from different medical-sports groups, revealing that the requirements of the sport linked to their action abilities provides them with different Imagery abilities. These results clearly influence the prescription of imagery training programs for different groups taking into account different medical-practice groups.

Keywords: Imagery, Boccia, expertise, mental training
\end{abstract}

\section{INTRODUCTION}

Imagery (IM) is a complex construct and several conceptualizations are used to describe its different aspects. IM can be considered as the creation or recreation of an experience from information kept in memory of sensitive, perceptual and affective characteristics. It may occur in the absence of a real stimulus antecedents normally associated with the actual experience (Simonsmeir \& Buecker, 2017; Morris, Spittle, \& watt, 2005; Fletcher, 2005). Usually, the ability to recreate an experience is related to former experiences and the resultant physiological and psychological effects. According to Cumming \& Williams (2012), IM is a relevant cognitive process to produce motor actions and is a useful mental training technique used by athletes to improve their performance. Furthermore, IM is frequently used in processes of learning or relearning of motor abilities within "clinical and rehabilitative populations" (Cumming \&
Ramsey, 2009). The IM ability can be evaluated in three different categories, in isolation or combined, such as the kinesthetic, internal visual and external visual, so as to get better results in its evaluation and application processes (William et al., 2012). In literature on the use of IM in sport, the applied model of imagery use, proposed by Martin, Moritz, and Hall (1999) is one of the most commonly used and with better results (Cumming \& Williams, 2013).

In this model, the practice context is considered determinant for the way IM is used, with repercussions including at the results level. Therefore, the individual's IM ability to reproduce images, as well as the practice context and the intrinsic and extrinsic motivation to do the IM exercise can be considered as crucial aspects to determine the final result (Martin et al., 1999). Besides that, Martin et al. (1999) claim that individuals with good movement IM ability learn better and improve their physical

Manuscript received at April 27 ${ }^{\text {th }} 2017$; Accepted at May 30 2017

${ }^{1}$ Departamento de Ciências do Desporto, Universidade da Beira Interior, Covilhã, Portugal.

${ }^{2}$ CreativeLab, CIDESD, Research Centre in Sports Sciences, Health Sciences and Human Development, Vila Real, Portugal.

${ }^{3}$ Polytechnic Institute of Castelo Branco, Higher School of Education, Castelo Branco, Portugal.

${ }^{4}$ Research in Education and Community Intervention, RECI, Portugal.

* Corresponding author: Universidade da Beira Interior, Departamento de Desporto, R. Marquês de Ávila e Bolama, 6201-001 Covilhã. E-mail: bruno.travassos@ubi.pt 
performances. Based on former assumptions, Cumming and Williams (2013) have recently redesigned the applied model of Imagery use (Figure 1), in which the importance of the influence of the individual's IM ability in movement imagery was highlighted (Koehn, Stavrou, Young, \& Morris, 2016). In order to assess the individual's differences in IM the Movement Imagery Questionnaire - 3 (William et al., 2012) stands out. This has been translated and adapted to the Portuguese population by Mendes et al. (2016) as the instrument that best distinguishes the IM ability.

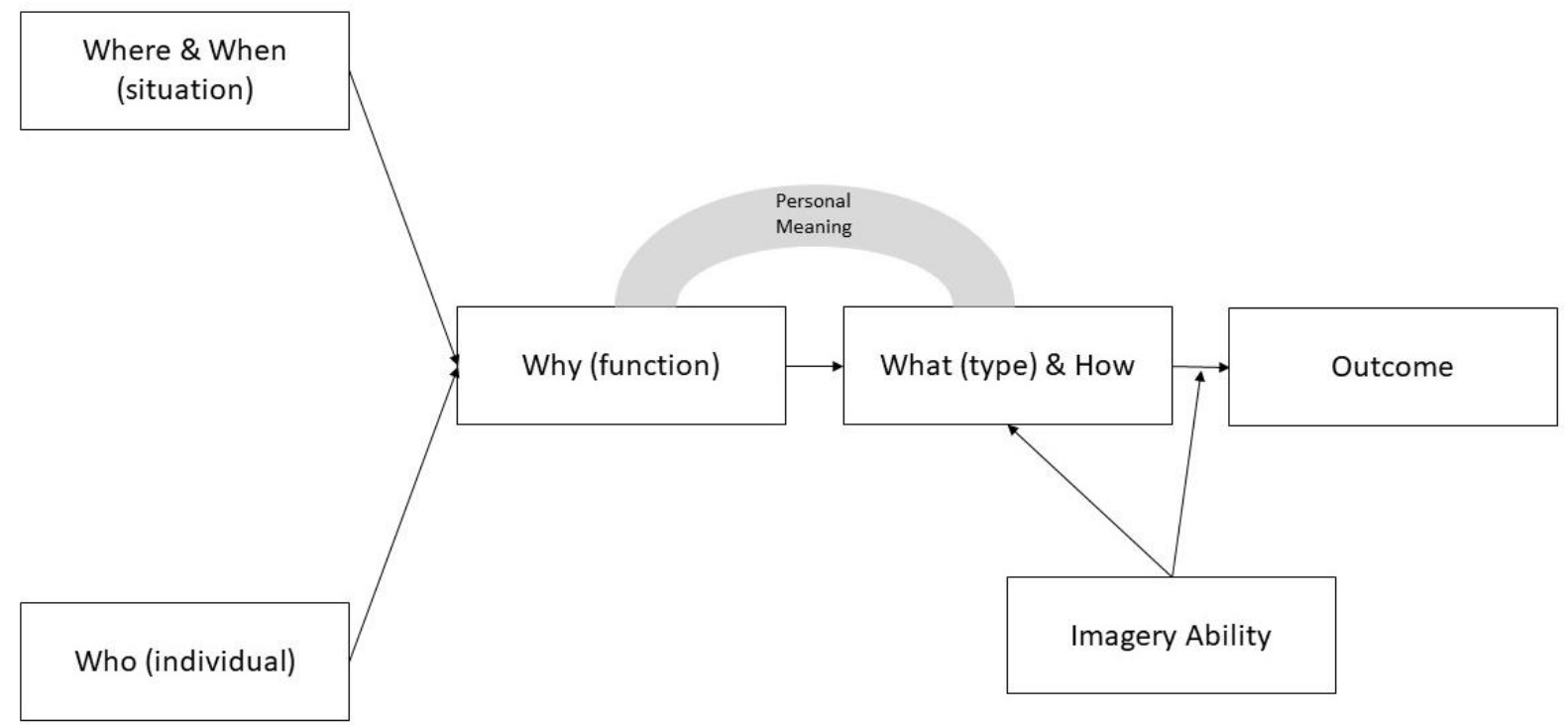

Figure 1. Revised Model of Imagery (adapted from Cumming \& Williams, 2012: p. 246)

As aforementioned, in this model, the central aspect of the IM ability is related to the ability of an athlete to experience vivid and controllable mental imagery (Hall \& Martin, 1997), within an internal and external perspective (Murphy \& Martin, 2002).On the internal visual perspective, the individual imagines seeing through his/her own eyes, i.e., he/she visualizes him/herself in the first person doing the movement; on the external visual perspective, the individual visualizes him/herself in the third person, watching the movement outside his/her own body (Holmes \& Calmels, 2008; Williams et al., 2012). Thus, athletes with a more developed IM ability show better performance than less capable athletes in giving details and manipulating their imagery (Felts \& Landers, 1983). According to Paivio (1985), the individual differences in IM ability may be related to genetic differences and to experience in sport (Gregg, Hall, McGowan, \& Hall, 2011; Williams \& Cumming, 2012). Taking into account that IM ability may be improved with practice (Rogers, Hall, \& Buckolz, 1991) and that high competitive level athletes practice more IM than lower level athletes (Cumming \& Hall,
2002), there are naturally differences in IM ability between these athletes. Therefore, athletes with a more developed IM ability show better performance than less capable athletes in giving details and manipulating imagery (Felts \& Landers, 1983). According to Mahoney and Avener (1977), the IM perspective is one of the factors that can influence IM in sport performance, referring to the internal perspective (visualization in the first person) as the most effective in elite athletes and a higher use of the external perspective (visualization as a spectator of oneself) in lower level athletes. Confirming former results, Mendes (2015), through a comparison of IM ability among Elite swimmers (National Team athletes), Sub-Elite (federate athletes competing at National level) and NonElite (swimmers who swim at least twice a week), drew the conclusion that the performance level is related to IM ability. Elite swimmers show better IM ability than the other groups.

Boccia is a sport adapted to precision throwing, played mainly by people who have cerebral palsy and/or with movement and coordination limitations. Those may be grouped 
into 4 groups: $\mathrm{BC} 1$ - players who can compete with the aid of assistants, who should keep out of the athlete's game area; $\mathrm{BC} 2$ - players who cannot be assisted; BC3 - players who are functionally more limited, and who cannot throw balls and need assistance; BC4 - players with other disabilities, but who are totally autonomous in what the functional requirements of the game are concerned, and who are not allowed to receive any assistance (Boccia International Sports Federation, 2013). According to Bodas et al. (2007), this sport requires an effort and ability scale, variable according to the physical abilities of its players, whereas psychologically it requires maximum focus on the attention and concentration levels, before and between throws, so that coordination and muscle control can be made easier.

Although IM has been studied in several studies in sport, there is hardly any research in adapted sport. According to Hall (2001), sports based on the use of discreet tasks, such as throwing a ball, provide a lot of opportunities for the use of IM, and Boccia is a sport adapted to precision throwing with potential for its use. Previous research, highlighted the importance of research on the IM ability within disabled athletes to confirm the existing results in sport (Goudas, Kontou, and Theodorakis, 2006). According to that, in a study that examined the use of IM in adapted sports (visual impairments), it was concluded that goalball participants used IM with similar functions to non-disabled athletes, privileging their cognitive and motivational functions, mainly within an internal perspective (Eddy \& Mellalieu, 2003). Anacleto, Dias, Ribeiro, Corte-Real, and Fonseca (2012) also revealed that Boccia athletes, presented greater ability and frequency to use IM when compared to those of a lower level. Therefore, and with the purpose to improve the knowledge of IM in adapted sport, specifically in Boccia, the aim of this study is to analyse and compare IM ability in federate and non-federate Boccia athletes, and among federate Boccia medical sport groups, according to BISFed regulation (2013). IM ability is expected to be better in federate athletes than in non-federate athletes. Similarly, according to the results observed by Eddy and Mellalieu
(2003), bearing in mind motor limitations in different groups and the need to focus on cognitive and motivational functions in order to reach the goals, a higher IM ability is expected in group B3 than in other groups.

\section{METHOD}

\section{Experimental Approach to the problem}

A comparative study between federate and non-federate Boccia athletes, and among federate Boccia medical sport groups was developed to identify the differences on the IM ability between groups. Participants were chosen using criteria (federates, non-federates and level of Boccia medical groups) according to the aim of this study, which is an intentional example, and it is not of the probability type (Tuckman \& Harper, 2012). Any participant was excluded from the study after given the duly informed consent.

Regarding data collection, all the instructions of the procedures were written so that each and every one could receive the same instructions. The instrument was applied in the local of practice of each participant with a maximum of 5 participants per collection to ensure concentration to answer the questionnaire. The data collection was developed before the training sessions.

\section{Participants}

Forty two Boccia athletes (male $\mathrm{N}=29$; female $\mathrm{N}=13$ ) at an average age of 35.8 (SD = 11.19), with at least 2 years of practice have participated in this study. Eighteen of the participants were not federated and practiced at least once a week, and 24 participants were federated and practiced at least twice a week (6 of these were in the National Team). According to the classification into medical sport groups of the federated athletes and following the BisFed rules (2013), 5 athletes from group BC1, 11 athletes from group $\mathrm{BC} 2$, and also 8 from group $\mathrm{BC} 3$ have participated in this study.

The participants were duly informed about the study, about its aims as well as its procedures. Only the participants who gave their consent were included, and they gave their written consent according to the Declaration of Helsinki (WMA, 2013). 


\section{Instruments}

MIQ-3 (Williams et al., 2012) is an instrument that consists of twelve items which are grouped in three subscales which assess the kinesthetic, internal and external visual imagery. For each imagery four basic mental movements are created (knee lift, jump, move arm, bend from waist), and to measure clearness during the mental visualization of those movements two Likert type scales with seven measuring points are used, which go from "very difficult to see" (visual imagery) or "very difficult to feel" (kinesthetic imagery) to "very easy to see" or "very easy to feel". The Portuguese version of MIQ-3 validated by Mendes, Marinho, Petrica, Silveira, Monteiro, and Cid (2016) was used for this study. Taking into consideration the participants' physical limitations in this study, the kinesthetic imagery was not assessed. The participants were provided with definitions of the internal and external visual imagery before filling in the questionnaire. The internal visual imagery was defined as "when you see yourself doing the movement from an internal point of view, or in the first-person perspective, it is as if you were really inside yourself, doing and watching the action through your eyes" (Mendes, Marinho, Petrica, Silveira, Monteiro, \& Cid, 2016). The external visual imagery was defined as "when you see yourself doing the movement from an external point of view or in the third person, as if you were watching a DVD" (Mendes et al., 2016).

The calculation of Cronbach Alfa value $(\alpha)$ showed excellent internal consistency for each of the two subscales used (Internal Visual Imagery $\alpha=$.93; External Visual Imagery $\alpha=.92$ ). The IM estimation in each imagery was obtained through the arithmetic average of the estimations recorded in each of their items, each imagery showing an estimation between 1 and 7 marks.

\section{Data collection}

The instrument was always used in similar places and conditions for all participants, with groups with a maximum number of 5 athletes, in which the adequate conditions for the questionnaire were guaranteed. Data was collected in two days. The first day was for the group of non-federate athletes and the second day was for the federate athletes. The average time used to fill in the questionnaire was 25 minutes for each group of participants.

\section{Statistical Analysis}

Statistics was carried out following the method of interference based on the magnitude of the effects. The variation intervals to classify the magnitude of effects ( $d$ Cohen) were as follows: 0-0.2, trivial; 0.21-0.6, short; 0.61-1.2, moderate; 1.21-2.0, long; $\geq 2.0$, very long. The considered variation probabilities were as follows: $\leq 25 \%$, low probability, $25-75 \%$, possible, 75-95\%, probable, 95-99\%, very probable; $\geq 99 \%$, probably (Hopkins, 2009).

\section{RESULTS}

\section{Effects of expertise in Boccia athletes' IM ability}

Results showed a great effect of expertise ( $d=$ 1.14 (90\%CI: $0.59-1.70)$, 25-75\%, possible) in IM ability. Federate athletes showed higher average scores in the subscales of MIQ-3 (Table $1)$. The comparison between federate and nonfederate Boccia athletes in both subscales of MIQ3 showed a great effect ( $d=1.55$ (90\%CI: 0.97 $2.14), 25-75 \%$, possible) in the Internal Visual subscale and a moderate effect $(d=1.12$ (90\%CI: $0.57-1.67), 25-75 \%$, possible) in the External Visual subscale.

Table 1

Results of the MIQ-3 and the two subscales with the comparison between Federate and Non-federate athletes

\begin{tabular}{|c|c|c|c|c|c|c|c|}
\hline & \multirow{2}{*}{$\mathrm{n}$} & \multicolumn{2}{|c|}{ MIQ-3 } & \multicolumn{2}{|c|}{ Internal Visual Imagery } & \multicolumn{2}{|c|}{ External Visual Imagery } \\
\hline & & M & sd & $\mathrm{M}$ & $\mathrm{sd}$ & $\mathrm{M}$ & Sd \\
\hline Federate & 24 & 4.09 & 1.04 & 4.09 & 0.92 & 4.10 & 0.99 \\
\hline Non-federate & 18 & 3.06 & 0.61 & 2.92 & 0.35 & 3.19 & 0.38 \\
\hline
\end{tabular}


Effects of the medical-performance group in Boccia athletes' IM ability

Results showed a partial effect in the medicalperformance group in IM ability. In general, the results of MIQ-3 showed a moderate effect ( $d=$ 0.83 (90\%CI: $0.04-1.63), \quad \leq 25 \%$, low probability), though with low probability, between $\mathrm{BC} 3$ and $\mathrm{BC} 2$ groups with higher scores in IM ability for group BC3 (Table 2). The internal visual subscale showed a moderate effect $(d=1.15$ (90\%CI: 0.33 - 1.97), 25-75\%, possible) between groups $\mathrm{BC} 3$ and $\mathrm{BC} 2$. The remaining comparisons in Internal Visual subscale and External Visual subscale did not show any effect between medical sport groups of Boccia athletes.

Table 2

Results of the MIQ-3 and the two subscales with the comparison between groups of analysis (BC1, BC2 e BC3)

\begin{tabular}{lccccccc}
\hline & \multirow{2}{*}{$\mathrm{N}$} & \multicolumn{3}{c}{ MIQ-3 } & \multicolumn{2}{c}{ Internal Visual Imagery } & \multicolumn{2}{c}{ External Visual Imagery } \\
\cline { 2 - 7 } & & $\mathrm{M}$ & $\mathrm{sd}$ & $\mathrm{M}$ & $\mathrm{sd}$ & $\mathrm{M}$ & sd \\
\hline BC1 & 5 & 4.18 & 1.28 & 4.10 & 1.37 & 4.25 & 1.28 \\
$\mathrm{BC} 2$ & 11 & 3.75 & 0.79 & 3.73 & 0.57 & 3.77 & 0.65 \\
$\mathrm{BC} 3$ & 8 & 4.53 & 1.03 & 4.59 & 0.87 & 4.47 & 1.16 \\
\hline
\end{tabular}

$\mathrm{M}=$ Mean; $\mathrm{sd}=$ Standard Deviation

\section{DISCUSSION}

The aim of the present study was to analyse and compare IM ability in Portuguese federate and non-federate Boccia athletes, and between federate medical sport Boccia groups according to BISFed regulation (2013). Several studies have shown benefits of IM in performance and learning of motor abilities in athletes at different competitive levels. However, there are hardly any studies carried out in adapted sport. As expected, through scores recorded in MIQ-3, results confirmed that IM ability in Boccia athletes differs according to their competitive level. In general, federate athletes show higher IM ability throughout MIQ-3 as well as in each of its assessed subscales. Concerning the effect of the medical-performance group of federate athletes $(\mathrm{BC} 1, \mathrm{BC} 2$, and $\mathrm{BC} 3)$ there were differences between groups $\mathrm{BC} 2$ and $\mathrm{BC} 3$ in IM in general. However, when each of the subscales is assessed individually, there are no differences between medical-performance groups in the External Visual subscale. Internal Visual subscale showed differences between groups $\mathrm{BC} 2$ and $\mathrm{BC} 3$.

The results of the comparison between federate and non-federate athletes confirm the results of former research in several sports, highlighting the importance of time and practice level in athletes' IM ability (Gregg \& Hall, 2006; Roberts et al., 2008). For example, recently Mendes (2015) have realized that Elite, Sub-Elite and Non-Elite swimmers differed in IM ability and in each of the Internal and External Visual subscales, in which the Elite group showed the highest scores. Despite the evident differences between Internal and External Visual subscales, results in the present research showed a greater effect among federate and non-federate athletes in Internal Visual subscale than in External Visual subscale. These results are consistent with former results with Boccia athletes, who showed a general tendency to use of Internal Visual IM more frequently than an External Visual IM (Anacleto et al., 2012). The reason for these differences is the correlation between the characteristics of the sport and the athletes' action abilities, which requires great focus on the understanding of the task in the first person. In Internal Visual IM the athlete imagines him/herself doing the action in the first person, which allows him/her a greater control of abilities in which time and space awareness, and the perception and anticipation of possibilities for the action are important to carry out the ability (Anacleto et al., 2012; Holmes \& Calmels, 2008).

Dieffenbach et al. (2012) reached the conclusion that not only athletes but also coaches at Paralympics Games level give great importance to psychological skills in training and in competition, and IM is claimed to be one of the 12 most important skills. Assuming that the ability to imagine is different from person to 
person, it must be identified before an IM training program so that it can be adjusted to an assertive imagery plan, either according to the level of the participants or according to the requirements of the sport. Considering the results of the comparison between federate and non-federate athletes one may conclude that IM training for Boccia athletes should mainly focus on the development of the Internal perspective of IM to meet the requirements of the sport (Anacleto et al., 2012; Holmes \& Calmels, 2008; Mendes, Marinho, \& Petrica, 2015; White \& Hardy, 1995).

The results can also be associated to the importance of neural generation, which represents neural networks involving top-down sensorial, perceptual and affective characteristics, which are mainly under the conscious control of the individual, and which may occur in the absence of perceptual assessment, they are functionally equivalent to the visualized sport action (Holmes \& Calmels, 2008). When the repetition of the movement is associated to training frequency, biologic theories refer that the benefits of the action in cognition are due to the concentration of neurotransmitters, such as epinephrine, which are responsible for stimulating higher brain centres, thus neurotrophically stimulating the brain and improving brain activities (Gomez-Pinilla, Vaynman, \& Ying, 2008; Boxtel et al., 1997). Therefore, associating IM to the practice of a specific movement will allow a greater brain plasticity and, consequently, a better cognitive and motor performance (Erickson, Hillman, \& Kramer, 2015).

Regarding the effect of medical-sports groups in the athletes' IM ability, it is important to assess their psychological needs according to their abilities (Bodas et al., 2007). Group BC3 athletes were the ones who showed higher IM ability in general. However, there were only statistical effects though with low probability between groups $\mathrm{BC} 3$ and $\mathrm{BC} 2$. Besides that, considering both internal and external visual subscales in MIQ-3, there were only differences in internal visual subscale between groups $\mathrm{BC} 3$ and $\mathrm{BC} 2$. Group $\mathrm{BC} 2$ consists of athletes who cannot be assisted and who carry out the action themselves, whereas group BC3 consists of athletes with more limited functional characteristics, who cannot throw balls and need assistance. The external visual perspective is more important in the execution of tasks in which method or body coordination is important, i.e., visualizing how the movement or action should be done. Internal visual perspective is more important in abilities in which awareness of time is important for the execution of tasks (White \& Hardy, 1995). Regarding ability differences between groups BC2 (visualizes and moves autonomously) and BC3 (visualizes and only gives the assistant instructions with no movement associated), the differences between medical-sports groups in the different subscales can be considered to be in their own ability of action and in the demands of the task in face of their abilities. Lower scores in IM ability and especially in IM subscale among BC2 athletes can be caused by a less frequent use of IM abilities in view of its higher number of possibilities of action and the fact that they are not dependent on an assistant to play. However, future studies are necessary in order to confirm the present results due to the reduced dimension of the sample in the different medical-sports groups. Really, the reduced sample used is a limitation of the study than needs to be considered in further studies. Also, future studies should consider not only the application of the MIQ-3 to evaluate the IM of participants of Boccia of different levels of expertise (federate vs nonfederate) and different medical groups (BC1, BC2 and $\mathrm{BC} 3$ ), but also correlate such results with the analysis of the performance of participants (Erickson, Hillman, \& Kramer, 2015).

\section{CONCLUSIONS}

The present results match the results in former studies which show an effect of expertise in athletes' imagery ability. Likewise, Boccia participants show that tendency. Federate athletes show better IM ability in general, revealing a better ability to recreate possibilities of practice, especially those concerning internal perspective of IM. Differences between athletes from different medical-sports groups were also evident, which shows that the requirements of the sport linked to their action abilities provides them with different IM abilities. These results 
clearly influence the prescription of IM training programs for different groups considering different medical-practice groups. Likewise, the relationship with enhancement of performance should be considered and assessed.

\section{Acknowledgments: \\ Nothing to declare.}

\section{Conflict of interests:}

Nothing to declare.

\section{Funding:}

Nothing to declare.

\section{REFERENCES}

Anacleto, I., Dias, C., Ribeiro, J., Corte-Real, N., \& Fonseca, A. (2012) Imagery in adapted sport: A study with some of the best Portuguese boccia athletes. Revista Portuguesa de Ciências do Desporto, 12(3), 58-76. ISSN: 1645-0523

BISfed. (2013). Boccia Classification Rules (2 ${ }^{\mathrm{a}}$ ed.).

Bodas, A., Lázaro, J., \& Fernandes, H. (2007) Perfil psicológico de prestação dos atletas paralímpicos Atenas 2004. Motricidade, 3(3), 33-43.

Boxtel, M., Pass, F., Houx, P., \& Jolles, J. (1997). Aerobic capacity and cognitive performance in a crosssectional aging study. Medicine and Science in Sports and Exercise, 29(10),1357-1365. DOI: 10.1097/00005768-199710000-00013

Cumming, J., \& Hall, C. (2002). Deliberate imagery practice: The development of imagery skills in competitive athletes. Journal of Sports Sciences, 20(2), 137-145. DOI: $10.1080 / 026404102317200846$

Cumming, J., \& Ramsey, R. (2009). Imagery interventions in sport. In S. D Mellalieu \& S. Hanton (Eds.), Advances in applied sport psychology: A review (pp. 5-36). London: Routledge. DOI: 10.13140/2.1.2619.2322

Cumming, J., \& Williams, S. (2012). The role of imagery in performance. In S. Murphy (Ed), Handbook of Sport and Performance Psychology (pp. 213-232). New York, NY: Oxford University Press. DOI: 10.13140/2.1.3274.5925

Cumming, J., \& Williams, S. (2013). Introducing the revised applied model of deliberate imagery use for sport, dance, exercise, and rehabilitation. Movement \& Sport Sciences - Science \& Motricité, 82, 69-81. DOI: $10.1051 / \mathrm{sm} / 2013098$

Dieffenbach, K., \& Statler, T. (2012). More Similar than Different: The Psychological Environment of Paralympic Sport. Journal of Sport Psychology in Action, 3(2), 109-118. DOI: $10.1080 / 21520704.2012 .683322$
Eddy, K., \& Mellalieu, S. (2003). Mental imagery in athletes with visual impairments. Adapted Physical Activity Quarterly, 20(4), 347-368. DOI: 10.1123/apaq.20.4.347

Erickson, K., Hillman, C., \& Kramer, A. (2015). Physical activity, brain, and cognition. Behavioral Sciences, $4, \quad 27-32$ DOI: 10.1016/j.cobeha.2015.01.005

Feltz, D., \& Landers, D. (1983). The effects of mental practice on motor skill learning and performance: A meta-analysis. Journal of Sport Psychology, 5(1), 25-27. DOI: $10.1123 /$ jsp.5.1.25

Fletcher, S. (2005). Technical Aids to Imagery. In T. Morris, M. Spittle, \& A. Watt (Eds.), Imagery in Sport (pp. 237-266). Champaign, IL: Human Kinetics.

Gregg, M., Hall, C., McGowan, E., \& Hall, N. (2011). The relationship between imagery ability and imagery use among athletes. Journal of Applied Sport Psychology, 23(2), 129-141. DOI: $10.1080 / 10413200.2010 .544279$

Goudas, M., Kontou, M., \& Theodorakis, Y. (2006). Validity and reliability of the Greek version of the Test of Performance Strategies (TOPS) for athletes with disabilities. Japanese Journal of Adapted Sport Science, 4, 29-36.

Gregg, M., \& Hall, C. (2006). Measurement of motivational imagery abilities in sport. Journal of Sports Sciences, 24(9), 961-971. DOI: $10.1080 / 02640410500386167$

Gomez-Pinilla, F., Vaynman, S., \& Ying, Z. (2008). Brain-derived neurotrophic factor functions as a metabotrophin to mediate the effects of exercise on cognition. Eur J Neurosci, 28(11), 2278-2287. DOI: $10.1111 / j .1460-9568.2008 .06524 . x$

Hall, C. (2001). Imagery in sport and exercise. In R. N. Singer, H. Hausenblas, \& C. Janelle (Eds.), Handbook of sport psychology (2a ed., pp. 529-549). New York: John Wiley \& Sons.

Hall, C., \& Martin, K. (1997). Measuring movement imagery abilities: A revision of the movement imagery questionnaire. Journal of Mental Imagery, $21(1-2), 143-154$.

Holmes, P., \& Calmels, C. (2008). A neuroscientific review of imagery and observation use in sport. Journal of Motor Behavior, 40, 433-445. DOI: 10.3200/JMBR.40.5.433-445

Hopkins, W., Marshall, S., Batterham, A., \& Hanin, J. (2009). Progressive statistics for studies in sports medicine and exercise science. Medicine $\mathcal{E}$ Science in Sports \& Exercise, 41(1), 3-12. doi: 10.1249/MSS.0b013e31818cb278.

Koehn, S., Stavrou, N., Young, J., \& Morris, T. (2016). The applied model of imagery use: Examination of moderation and mediation effects. Scandinavian Journal of Medicine E Science in Sports, 26 (8), 975984. Doi: $10.1111 /$ sms. 12525

Mahoney, M., \& Avener, M. (1977). Psychology of the elite athlete: An exploratory study. Cognitive Therapy and Research, 1(2), 135-141. DOI: 10.1007/BF01173634 
Martin, K., Moritz, S., \& Hall, C. (1999). Imagery use in sport: A literature review and applied model. The Sport Psychologist, 13(3), 245-268. DOI: 10.1123/tsp.13.3.245

Mendes, P., Marinho, D., \& Petrica, J. (2015). Comparison between genders in imagery ability in Portuguese basketball practitioners. Journal of Physical Education and Sport, 15(3), 391-395. DOI: 10.7752/jpes.2015.03058

Mendes, P. (2015). Tradução e Validação do Movement Imagery Questionnaire - 3, versão Portuguesa, e as habilidades de Imagery em atletas de modalidades distintas. $\mathrm{PhD}$ thesis, University of Beira Interior, Covilhã, Portugal.

Mendes, P., Marinho, D., Petrica, J., Silveira, P., Monteiro, D., \& Cid, L. (2016). Tradução e Validação do Movement Imagery Questionnaire - 3 (MIQ-3) com Atletas Portugueses. Motricidade, 12(1), 149-158. DOI: 10.6063/motricidade.7006

Morris, T., Spittle, M., \& Watt, A. P. (2005). Imagery in sport. Campaign, IL: Human Kinetics.

Murphy, S., \& Martin, K. (2002). The use of imagery in sport. In T. S. Horn (Ed.), Advances in sport psychology ( $2^{\text {nd }}$ ed., pp. 405-439). Champaign, IL: Human Kinetics.

Paivio, A. (1985). Cognitive and motivational functions of imagery in human performance. Canadian Journal of Applied Sport Sciences, 10(4), 22S-28S.

Roberts, R., Callow, N., Hardy, L., Markland, D., \& Bringer, J. (2008). Movement imagery ability: Development and assessment of a revised version of the Vividness of Movement Imagery Questionnaire. Journal of Sport \& Exercise Psychology, 30(2), 200-221. DOI: 10.1123/jsep.30.2.200
Rodgers, W., Hall, C., \& Buckolz, E. (1991). The effect of an imagery training program on imagery ability, imagery use, and figure skating performance. Journal of Applied Sport Psychology, 3(2), 109-125. DOI: $10.1080 / 10413209108406438$

Simonsmeier, B., \& Buecker, S. (2017) Interrelations of Imagery Use, Imagery Ability, and Performance in Young Athletes, Journal of Applied Sport Psychology, 29, 1, 32-43. DOI: 10.1080/10413200.2016.1187686

Tuckman, B., \& Harper, B. (2012). Conducting Educational Research ( $6^{\mathrm{a}}$ ed.). United Kingdom: Rowman Littlefield Publishers, Inc.

White, A., \& Hardy, L. (1995). Use of different imagery perspectives on the learning and performance of different motor skills. British Journal of Psychology, 86(2), 169-180. DOI: 10.1111/j.20448295.1995.tb02554.x

Williams, S., \& Cumming, J. (2012). Athletes' ease of imaging predicts their imagery ability and observational learning use. Psychology of Sport and Exercise, 13(4), 363-370. DOI: 10.1016/j.psychsport.2012.01.010

Williams, S., Cumming, J., Ntoumanis, N., NordinBates, S., Ramsey, R., \& Hall, C. (2012). Further validation and development of the Movement Imagery Questionnaire. Journal of Sport \& Exercise Psychology, 34(5), 621-646. DOI: 10.1123/jsep.34.5.621

World Medical Association. (2013). WMA Declaration of Helsinki: Ethical principles for medical research involving human subjects. Fortaleza: WMA 